\title{
ANALISIS DAMPAK INTERNET TERHADAP PERKEMBANGAN BAHASA SISWA SEKOLAH DASAR KELAS III
}

\author{
Hany Handayani ${ }^{1}$, Anwar Sanusi ${ }^{2}$ \\ 1 Program Studi Pendidikan Guru Sekolah Dasar, \\ Sekolah Tinggi Keguruan IImu Pendidikan Purwakarta \\ ${ }^{2}$ Departemen Pendidikan Bahasa Arab, \\ Universitas Pendidikan Indonesia \\ 1hanyhandayani@upi.edu \\ 2anwarsanusi@upi.edu
}

\begin{abstract}
The era of digitalization or the internet as it is today we need to be vigilant of all incoming information because it can affect children's development. One of the student developments that we need to optimize is language development. Language is a unifying nation. The purpose of this study is to describe the impact of the internet on the language development of elementary school students. The research method used in this research is the case study method. The research subjects consisted of nine third grade elementary school students in one elementary school in West Java in the Academic Year 2019/2020. The research instruments were observation sheets and interviews. The data obtained were analyzed with descriptive statistics. The results showed that the internet had a considerable impact on the language development of third grade elementary school students. However, a deeper analysis needs to be done whether the internet has a positive or negative influence on children's language development.
\end{abstract}

Keywords: Digital era, internet, language development, elementary school.

\begin{abstract}
ABSTRAK
Era digitalisasi atau internet seperti saat ini kita perlu waspada terhadap segala informasi yang masuk karena dapat memengaruhi perkembangan anak. Salah satu perkembangan siswa yang perlu kita optimalkan adalah perkembangan bahasa. Bahasa merupakan salah satu pemersatu bangsa. Tujuan dari penelitian ini adalah untuk mendeskripsikan dampak internet terhadap perkembangan Bahasa siswa sekolah dasar. Metode penelitian yang digunakan dalam penelitian ini adalah metode studi kasus. Subjek penelitian berjumlah sembilan orang siswa SD kelas III pada salah satu SD di Jawa Barat Tahun Akademik 2019/2020. Instrumen penelitiannya berupa lembar observasi dan wawancara. Data yang diperoleh dianalisis dengan statistik deskriftif. Hasil penelitian meunjukan bahwa internet memberikan dampak cukup sebesar terhadap perkembangan bahasa siswa SD kelas III. Namun perlu dilakukan analisis lebih dalam lagi apakah internet memberikan pengaruh positif atau negatif terhadap perkembangan bahasa anak.
\end{abstract}

Kata kunci: Era digital, internet, perkembangan bahasa, sekolah dasar. 
Didaktik : Jurnal IImiah PGSD STKIP Subang, ISSN Cetak : 2477-5673 ISSN Online : 2614-722X Volume VI Nomor 01, Juni 2020

\section{A. Pendahuluan}

Hidup di era digital ini memiliki pengaruh yang signifikan bagi masyarakat dunia. Hal ini terjadi karena dipengaruhi oleh meningkatnya perkembangan teknologi informasi dan komunikasi dari berbagai pola konsumtif seluruh lapisan masyarakat (Mislikhah, 2014); (Gialamas, Nikolopoulou \& Koutromanos, 2013). Konsekuensinya, satu sisi melahirkan nilai-nilai positif dan mampu mengangkat taraf hidup manusia, Namun, di sisi lain, perkembangan teknologi informasi dan komunikasi jika tidak dibingkai dengan nilai-nilai etika dan estetika hanya akan melahirkan keresahan, kerusakan dan kehancuran bagi manusia (Zakarija, 2010).

Utilitas teknologi informasi dan komunikasi turut pula berimbas pada dunia pendidikan di Indonesia. Faktanya, Stakeholder pendidikan sudah banyak menerapkan pemanfaatan media teknologi informasi dan komunikasi yang berbasis internet (interconnection networking) sebagai media pembelajaran, sarana pengembangan tenaga pengajar, dan pencarian berbagai informasi yang relevan dengan mata pelajaran (Gialamas, Nikolopoulou \& Koutromanos, 2013). Oleh karena itu, keunggulankeunggulan teknologi informasi dan komunikasi diharapkan bisa memacu dan meningkatkan mutu pendidikan. Dari sisi positif tentu saja semua pihak harus mendukung pemanfaatan teknologi informasi dan komunikasi di kurikulum sekolah (Zakarija, 2010).

Penggunaan media informasi dan komunikasi khususnya internet (interconnection networking) kini banyak dikonsumsi oleh remaja SMA termasuk siswa yang mengenyam bangku sekolah dasar (SD). hal tersebut dibuktikan dengan adanya data autentik dari Asosiasi Penyelenggara Jasa Internet Indonesia (APJII), bahwa pengguna internet (interconnection networking) berdasarkan tingkat pendidikannya seperti SMA/MA/Paket C, SMP/MTs/Paket B, SD/MI/Paket A, dan yang tidak sekolah, persentase penggunaannya secara berurutan 70,54 persen, 48,53 persen, 25,10 persen, dan 5,45 persen. (kompas.com).

Namun sangat disayangkan karena banyaknya siswa menggunakan internet (interconnection networking) jejaring sosial 
Didaktik : Jurnal IImiah PGSD STKIP Subang, ISSN Cetak : 2477-5673 ISSN Online : 2614-722X Volume VI Nomor 01, Juni 2020

seperti Facebook, BBM, Line, Whats App, Twitter, dan lain-lain seringkali disalah gunakan hingga dapat merusak karakter siswa. Padahal salah satu bentuk konkret keberhasilan dari suatu pendidikan adalah siswa memiliki kepribadian yang sopan dan santun (Mislikhah, 2014). Standar kepribadian yang sopan dan santun bisa ditentukan dengan tindak tanduk dan tutur kata dalam interaksi dan komunikasi sehari-hari.

Dewasa ini, bahasa yang digunakan siswa tidak lagi mencerminkan sebagai bangsa yang menjunjung tinggi nilai etika dan estetika. Salah satu manifestasi dari nilai etika dan estetika yang bisa dicermati adalah kesantunan berbahasa.

fakta yang diamati peneliti di media sosial dan sekolah, banyak siswa yang sudah mulai terkikis habis nilai kesantunannya, mereka dengan bebas berbahasa tanpa menyadari dan mempertimbangkan kepada siapa mereka berbahasa, sehingga bahasa yang mereka keluarkan cendrung tidak memiliki prinsip kesopanan (politeness principle). Misalnya, siswa dalam berkomunikasi dengan guru melalui media sosial maupun langsung cendrung menggunakan bahasa yang tidak hormat dan tidak menunjukkan sikap rendah hati. Selain itu, peristiwa bullying yang dilakukan antar sesama siswa di sekolah mengindikasikan bahwa identitas siswa yang menjunjung tinggi nilai kesopanan sudah hilang (Gialamas, Nikolopoulou \& Koutromanos, 2013).

Tayangan-tayangan kekerasan dan sadis di telivisi atau media sosial dengan menggunakan bahasa saru dan vulgar semakin merajalela, tontonan-tontonan seksual-liberalis semakin membudaya (Zakarija, 2010). Eksesnya, bahasa tersebut dipakai siswa dan mengejawantah menjadi bahasa populer dalam komunikasi sehari-hari khususnya di sekolah. Hal tersebut mengindikasikan bahwa perkembangan teknologi sangat memengaruhi pertumbuhan dan perkembangan bahasa siswa.

Menurut Leech sebagaimana dinukil (Mislikhah, 2014) bahwa dalam berkomunikasi harus memperhatikan prinsip kesopanan (politeness principle) dengan maksimmaksimnya, diantaranya: (1) maksim kebijakan dengan cara memprioritaskan kearifan berbahasa, 
Didaktik : Jurnal IImiah PGSD STKIP Subang, ISSN Cetak : 2477-5673 ISSN Online : 2614-722X

Volume VI Nomor 01, Juni 2020

(2) maksim kemurahan yang mengutamakan kesalutan/rasa hormat pada orang lain dan rasa hormat pada diri sendiri, dan (3) maksim kerendahan hati yang mengutamakan pujian pada orang lain dan rasa rendah hati pada diri sendiri. Ketiga prinsip ini pada dasarnya merupakan penuntun dan pengatur cara berkomunikasi siswa dalam kehidupan sehari hari di lingkungan keluarga, sekolah dan masyarakat..

Selain keluarga dan lingkungan masyarakat, Pendidikan berbahasa di sekolah pada era digital ini merupakan salah satu cara untuk memperbaiki dan menyelematkan bahasa siswa dari pengaruh negatif penggunaan media sosial yang berbasis internet (interconnection networking) (Fakhrunnisa, Astuti, \& Susilo, (n.d.).

Namun, hal itu tidak akan terwujud tanpa adanya realisasi konkret dari sekolah berupa strategi pengajaran yang mumpuni dan relevan dalam membentuk kesantunan bahasa siswa serta upaya kuratifnya dalam mengatasi bahasa siswa yang jauh dari nilai-nilai kesantunan. Oleh karena itu, peneliti akan membahas mengenai pengaruh era digital terhadap perkembangan bahasa siswa, strategi dalam pengajaran bahasa santun dan upaya kuratifnya dalam mengatasi bahasa siswa yang jauh dari nilai-nilai kesantunan.

\section{B. Metode Penelitian}

\section{Metode Penelitian}

Artikel ini mengadopsi penelitian kualitatif, dengan menggunakan pendekatan studi kasus. Studi kasus dipilih karena memungkinkan peneliti untuk mengeksplorasi hasil dari dampak internet terhadap perkembangan Bahasa siswa SD kelas III (Gable, 1994). Pada saat bersamaan, dengan melakukan studi kasus, peneliti diizinkan untuk membandingkan berbagai unit kasus.

\section{Subjek Penelitian}

Subjek merupakan siswa SD pada salah satu sekolah dasar di Jawa Barat Tahun Akademik 2019/2020 yang terdiri enam perempuan dan tiga laki-laki. Mereka berasal suku jawa, sunda, minang, batak dan melayu. Selain itu siswa berasal dari keluarga menengah keatas.

\section{Alat Pengumpul Data}

Penelitian ini menggunakan instrumen lembar observasi dan wawancara. Observasi dilakukan sebanyak lima 
Didaktik : Jurnal IImiah PGSD STKIP Subang, ISSN Cetak : 2477-5673 ISSN Online : 2614-722X Volume VI Nomor 01, Juni 2020

kali. Sedangkan setiap wawancara berlangsung selama satu sampai dua jam. Setelah data terkumpul langkah selanjutnya adalah dilakukan Focus Group Discussion (FGD) ini diadakan sebagai sarana untuk memeriksa dan mengecek kembali hasil observasi lapangan dan wawancara. Data kemudian ditranskrip, selanjutnya hasil transkip hasil wawancara dan observasi tersebut dikembalikan kepada partisipan untuk memastikannya keaslian. Partisipan juga diberi kesempatan untuk mengubah atau menghapus pernyataan dari transkrip.

\section{Analisis Data}

Tahap selanjutnya adalah tahap analisis data. Data dianalisis dengan menggunakan teori ground constructivist. Proses pengkodean berlangsung dalam dua tahap utama: line-by-line coding and accidental coding (Charmaz, 2006). Langkah pertama tahap analisis data, adalah hasil transkrip data dilakukan pengkodingan dan, di bandingkan setiap kode dan menggabungkan kode serupa, dan kemudian mengidentifikasi hasil tema yang muncul dari hasil pengkodingan tersebut.

\section{C.Hasil Penelitian dan Pembahasan}

Temuan penelitian ini menunjukkan sejauh mana internet berdampak pada perkembangan bahasa siswa. Semua guru saat ditanyai "apakah internet digunakan dalam proses pembelajaran?". Sebagian besar guru menjawab, "ya..pembelajaran kebanyakan menggunakan bantuan internet supaya siswa melek internet juga sejak dini." Guru beranggapan bahwa pembelajaran harus mengikuti perkembangan jaman, jaman sekarang adalah jaman digitalisasi. Namun, para guru tampaknya masih bingung terkait tugas dan pembelajaran yang harus berbasis internet apakah mempengaruhi perkembangan siswa apa tidak. Salah satu faktornya yang berkontribusi terhadap kebingungan guru didasarkan pada ketidaktersediaan instrument yang mampu menjawab hal tersebut.

Hal ini dapat dilihat dari hasil wawancara "apakah internet mempengaruhi perkembangan Bahasa siswa?". Hampir semua guru dalam penelitian ini hanya menggunakan internet dalam membantu proses pembelajaran 
Didaktik : Jurnal IImiah PGSD STKIP Subang, ISSN Cetak : 2477-5673 ISSN Online : 2614-722X Volume VI Nomor 01, Juni 2020

tanpa diperkahatikan apakah emmberikan dampak pada perkembangan Bahasa siswa apa tidaknya. Terlihat dari kutipan hasil wawancara berikut ini:

Ehmmm. . .... saya tidak melihat sampai kesitu yah tapi emmenag cukup membantu siswa (wawancara dengan AP, seorang guru Kelas $3 \mathrm{SD}$ pada tanggal 3 April 2018).

Terlepas dari kenyataan bahwa para guru berpikir bahwa internet itu membantu proses pembelajaran, guru kurang memahami pentingnya perkembangan bahasa dikembangkan sejak dini, mereka berpikir bahasa dapat berkembang sendiri melalui proses pembelajaran. Padahal perkembangan Bahasa penting penting sekali dikembangkan sejak dini disekolah. Pengembangaan bahasa dapat dilakukan melalui berbagai kegiatan disekolah salah satunya adalah melalui kegiatan literasi dari berbagai media/sumber ajar. Berdasarkan hal tersebut salah satu media yang mampu mengembangakan Bahasa siswa adalah internet.

Hasil observasi pada anakanak yang sedang belajar dikelas dan bermain ketika beristirahat, adalah
Berlarian, mengobrol bersama teman kelas lain. Siswa SF berkata bahwa "santuy aja gak usah bimbang Salah satu siswa lain yaitu GI berkata kita harus bisa berkonsolidasi dengan yang lain ... (Catatan Observasi, 12 April 2018)

Kata "santuy" merupakan kata yang biasa ada pada percakapan di dunia maya yang artinya santai. Sedangkan Bahasa konsolidasi untuk siswa kelas II SD sangat asing didengar tapi mereka sudah bisa memaknainya. Selain itu terlihat percakapan diantara mereka sangat komunikatif sekali. Pada proses ini anak telah melakukan peniruan terhadap apa yang dia dengar, atau di abaca.

Berdasarkan hasil wawancara hamper setiap hari guru menugaskan siswa untuk mengerjakan tugas dengan bantuan internet, melalui kegiatan membaca materi ajar.

....internet hampir setiap hari yach d rumah siswa menggunakannya untuk belajar, karena kami terbiasa menugaskan mencari infomarmasi melalui internet salah satunya yah materi ajar gt.... (Wawancara dengan guru $\mathrm{GH}$, guru kelas $3 \mathrm{SD}$ pada tanggal 12 Mei 2018)

Sejalan dengan itu hasil observasi menunjukan hal yang 
serupa, lebih jelas dapat dilihat dari hasil dengan orang tua berikut ini.

...kegiatan membaca di internetnya yach kami damping setiap harinya biasanya hanya 30 - 60 menit perharinya yach....(Wawancara Orang tua ST, 13 Mei 2018)

Menurut orang tua dengan siswa belajar menggunakan internet membantu mereka dalam mencari hal-hal yang mereka tidak ketahui. Selain itu mengembangakan kemampuan berbicara karena seiring dengan tingginya rasa ingin tahu mereka atas apa yang mereka baca di internet.

...iyah anak jd cerewet ini itu nanya, banyak banget yang pengen tahu dengan internet mereka bisa mencari tahu senidri bahkan jd baceo aja.(Wawancara dengan orang tua AA, 18 Mei 2018)

\section{Bahasa merupakan}

keterampilan yang sangat penting untuk dimiliki oleh setiap peserta didik, dan perlu ditanamkan sejak dini. Dalam berinteraksi dengan orang lain dan lingkungan disekitarnya anak harus mampu menyesuaikan diri, berusaha untuk dapat diterima oleh lingkungannya, mampu bekerja sama dengan yang lain, mampu menghargai orang lain, berempati terhadap orang lain, mengakui kelebihan orang lain, serta memiliki kemampuan untuk menyelesaikan permasalahan dengan baik Bahasa merupakan kunci utama. Hal ini perlu dimiliki oleh anak agar dapat diterima dengan keluarga, teman sebaya, masyarakat dan pergaulan di lingkungan yang lebih luas.

Sekolah sebagai lembaga pendidikan harus memfasilitasi perkembangan Bahasa anak, sesuai yang disampaikan dalam UndangUndang No. 20 Tahun 2003 mengenai sistem pendidikan nasional yang berbunyi "pendidikan adalah usaha sadar dan terencana untuk mewujudkan suasana belajar dan proses pembelajaran agar peserta didik secara aktif mengembangkan potensi dirinya untuk memiliki kekuatan spiritual, keagamaan, pengendalian diri, kepribadian, kecerdasan, akhlak mulia, serta keterampilan yang diperlukan dirinya, masyarakat, bangsa dan negara"

Tugas sekolah sebagai lembaga Pendidikan tidak hanya mengembangkan potensi anak dibidang akademik saja melainkan potensi anak yang lainnya termasuk perkembangan bahasanyanya. 
Hal ini dikarenakan bila seseorang memiliki Bahasa yang baik maka ia mampu untuk menjalin kerjasama, mempunyai rasa empati, atau piawai dalam menjalin komunikasi (Oktavianti, 2018).

Sekolah bisa mengembangkan keterampilan sosial pada anak dengan menggunakan metode, strategi, model pembelajaran serta pembiasaan agar anak memiliki keterampilan sosial yang baik.

\section{E. Kesimpulan}

Temuan penelitian menunjukan bahwa dalam internet memberikan dampak yang besar terhadap perkembangan bahasa anak. Perkembangan bahasa ini dapat dilihat dari aktivitas dikelas yang pemberian tugas mulai dari mencari materi, menjawab tugas pertanyaan, menggunakan internet perkembangan bahasa menulis, membaca nya sangat baik. Untuk penelitian selanjutnya, peneliti lain bisa menganalisis lebih dalam dampak internet memberikan dampak positif atau negatif terhadap perkembangan bahasa anak usia SD.

\section{DAFTAR PUSTAKA}

Charmaz, K. (2006). Constructing grounded theory: A practical guide through qualitative analysis. London, England: Sage.

Fakhrunnisa, A., Astuti, E. S., \& Susilo, H. (n.d.). Pengaruh Persepsi Kemanfaatan dan Sikap Pengguna Terhadap Minat Menggunakan Internet (Studi pada Tenaga Kependididkan di Fakultas IImu Administrasi Universitas Brawijaya Malang), Fakultas IImu Administrasi Universitas Brawijaya, Malang.

Gable, G. G. (1994). Integrating case study and survey research methods: An example in information systems. European Journal of Information Systems, 3, 112-126.

Gialamas, V., Nikolopoulou, K., \& Koutromanos, G. (2013). Student's Teacher Perceptions About The Impact of Internet Usage on Their Learning and Jobs, Computers \& Education, 1-7.

Kompas. (2018). Presentase Pengguna internet (interconnection networking) berdasarkan tingkat pendidikannya. Tersedia: kompas.com diakses /19/02/2018

Mislikhah, S. (2014). Kesantunan Berbahasa. International 
Journal of Islamic Studies, 1 (2). HIm. 285-296

Oktavianti I, \& Kanzunnudin M.

(2018). Pengembangan

Ketrampilan Sosial Siswa Pada

Pembelajaran IPS Berbasis

Keunggulan Lokal Melalui

Penerapan Reciprocal

Learning Berbantu Media

Cerita dan Metrik Ingatan.

https://www.researchgate.net/p

ublication/315996467accesse

d May 292018

Undang-Undang No. 20 Tahun 2003

tentang sistem pendidikan

nasional

Zakarija, A. (2010). Theory of Planned Behaviour Masihkah Relevan. [Online], Avalaible: http://zakarija.staff.umm.ac.id/fi les/2010/12/Theory-of-

Planned-Behavior-Masihkahrelevan1.pdf .[Accessed 7 April 2016]. 